\title{
Lipopeptides: Biosynthesis and Applications
}

\author{
Navpreet Kaur Walia and Swaranjit Singh Cameotra*
}

Institute of Microbial Technology, Chandigarh, India

\begin{abstract}
Microbial surfactants are amphiphilic molecules. They possess a strong tendency to reduce the interfacial tension among compounds. Biosurfactants possess diverse chemical structures and are nontoxic and hence are biodegradable. They have many applications in bioremediation, enhanced oil recovery, pharmaceutical and in food industry. In addition, biosurfactants have antifungal, antibacterial and antiviral properties. They are also found to have many therapeutic applications which as a result are very helpful for mankind in eradicating many pathogenic diseases. This review depicts the applications of lipopeptide biosurfactants in various fields.
\end{abstract}

Keywords: Bio surfactants; Applications; Biosynthesis; Lipopeptides

\section{Introduction}

Today environmental degradation is a major concern of policy makers and governments worldwide. Sustainable development is a challenging concept, with theories shaped by people's and organizations different worldviews, which in turn influence how issues are formulated and actions proposed. It is usually presented as the intersection between environment, society and economy, which are conceived of as separate although connected entities. We would argue that these are not unified entities: rather they are fractured and multilayered and can be considered at different spatial levels. The priority is always given to economy in policies and the environment is viewed as apart from humans. They are interconnected, with the economy dependent on society and the environment while human existence and society are dependent on, and within the environment. The separation of environment, society and economy often leads to a narrow technoscientific approach, while issues to do with society that are most likely to challenge the present socio-economic structure are often marginalized, in particular the sustainability of communities and the maintenance of cultural diversity. It is rightly said that "necessity is the mother of invention," so biosurfactants have got more emphasis than their synthetic counterparts because they are eco-friendly, biodegradable, less toxic and biocompatible than the synthetic surfactants Biosurfactants are surfactant active compounds which are produced by microorganisms. These are amphiphilic molecules and possess a spectacular tendency to reduce the interfacial tension of aqueous media. They contain both hydrophobic and hydrophilic moieties. They vary in their molecular size, structure, chemical properties and composition. Biosurfactants possess antifungal, antibacterial and antiviral quantities. Moreover, they also have anti-adhesive action against many pathogenic microorganisms. Biosurfactants are found to have many applications in enhanced oil recovery, bioremediation of heavy metals, pharmaceuticals, food and cosmetic industry. In addition, biosurfactants also have anti-microbial and anti-fouling properties. Microbial surfactants also play a vital role in swarming motility of microorganisms. There is a tremendous increase in global biosurfactants market in the last few years. According to Transperacy Market Research, both the household detergents and personal care segment will be the main focus that will contribute more than $56.8 \%$ of the global biosurfactants market in 2018. In addition, according to their survey Europe is at the top worldwide in production and consumption of biosurfactants, followed by North America. Another report given by Markets and Markets, the average of biosurfactant market in the whole world is expected to be $476,512.2$ tons by 2018 . Out of this total, $21 \%$ of volume consumption will come from developing regions such as Asia, Africa and Latin America. In 2013, the global biosurfactants market was $344,068.40$ tons and is expected to reach $461,991.67$ tons by 2020, growing at a CAGR of $4.3 \%$ from 2014 to 2020 . The patents on biosurfactants are continuously increasing worldwide.

This review represents the biosynthesis of lipopeptide biosurfactants and their applications in various fields.

\section{Biosurfactants: An Overview}

The first rhamnose containing biosurfactant was produced by Pseudomonas aeruginosa and it was first elucidated by Jarvis and Johnson in 1949 while the biotechnological concern in biosurfactants started in the 1980s, but at that time the use of biosurfactants was only restricted to oil recovery and bioremediation [1]. Initially, hydrocarbons were used as the main C-source for the biosurfactant production [2,3]. The main focus of this research was to identify or find the microbial species which can be able to produce biosurfactants, [4] explanation of their chemical structure $[5,6]$ and to study their surface active properties [6]. In 1980s, the biosurfactants became very interesting class of compounds but were much expensive than their synthetic counterparts [7]. The main cause of this economic drawback was the high substrate cost i.e. pure hydrocarbons. Moreover, microbial strains were pathogenic or due to lack of technology, it was difficult to handle at a large scale [8]. Even though, biosurfactants possess surfactant properties and show similar features with those of their chemically or petrochemically derived counterparts, their commercial interest in late 80s was only restricted to produce valuable sugars like L-rhamnose [1] for nutrition and pharmaceutical applications [9]. Currently, biosurfactants are used in wider way like in cosmetics [10], in food industry [11] bioremediation (Kosaric, Makkar and Cameotra,) [12,13] due the use of new cheaper and renewable resources as substrates [14] in comparison to the pure hydrocarbons. Nowadays, biosurfactants have many applications in medicine and agricultural sector $[15,16]$.

*Corresponding author: Swaranjit Singh Cameotra, Institute of Microbial Technology, Sec 39 A, Chandigarh, India, Tel: +91-0172-6665102; E-mail: ssc@imtech.res.in

Received January 22, 2015; Accepted March 17, 2015; Published March 24, 2015

Citation: Walia NK, Cameotra SS (2015) Lipopeptides: Biosynthesis and Applications. J Microb Biochem Technol 7: 103-107. doi:10.4172/19485948.1000189

Copyright: @ 2015 Walia NK, et al. This is an open-access article distributed under the terms of the Creative Commons Attribution License, which permits unrestricted use, distribution, and reproduction in any medium, provided the original author and source are credited 


\section{Lipopeptides}

Historical perspectives: The group of lipopeptides isolated during 1950s and 1960s from Bacillus sp. These contain more than 20 different peptides linked to various fatty acid chains. At present, more than a 100 different compounds can so be described.

Surfactin: It was 1968 when Arima et al. [18] from the supernatant of culture of Bacillus subtilis isolated an exocellular compound having an excellent biosurfactant activity. This compound was named surfactin and its structure was explicated as that of a lipopeptide [17]. It was exemplified as a valuable inhibitor of fibrin clot formation, an antibacterial, anti tumour and hypocholestrolemic agent.

Iturins: It is mentioned in the literature in 1949 (Walton and Woodruff) that Mycosubtilin was the first antifungal compound from Bacillus subtilis. Declambe in 1950 illustrated a second similar compound named iturin. Its name is associated to ituri, a region from Congo, where the compound was isolated from a soil sample. Iturin was first found to be a strong anti fungal agent with constrained anti bacterial activity against micrococcus and sarcina strains. During the 1970s and 1980s the accurate structure of these two compounds and similar compounds from the same species was described: mycosubtilin [18], bacillomycin L [19] identical to bacillomycin Lc or bacillopeptin [20], iturin A [21], iturin C [21], bacillomycins Dand F [22]. Mycocerein, an anti fungal peptide produced by Bacillus cereus was partially described and could belong to the iturin family [23].

Fengycin and plipastatin: Discovery of Fengycin and plipastatin was concomitant. In 1986, German [24] and Japanese teams [25] discovered simultaneously a third family of lipopetides: fengycin produced by bacillus subtilis and plipastatin produced from bacillus cereus. The first lipopetide was determined to be an anti fungal agent and later as a phospholipase A2 inhibitor. There was only a small structural difference between these two compounds and a doubt still exists today about them as well as their biological activities. Production of fengycin was also determined by Bacillus thuringiensis [26].

Kurstakins: A new family of lipopeptides from Bacillus sp. [27] with the use of Matrix assisted laser desorption/ionization (MALDI) so as to characterize and differentiate between different species or strains of bacillus spores discovered a new family of lipopeptides produced by Bacillus thuringiensis subsp. kurstaki and consequently called kurstakin. These compounds display anti fungal activity against Stachybotrys charatum and are mainly absorbed to the spore surfaces.

Lipopeptides structure: Lipopeptides are mainly produced by Bacillus species. These are low molecular weight compounds. Lipopeptides lowers the surface and interfacial tension more efficiently than glycolipids. Lipopeptides which are synthesized by Bacillus sp. have a good heterogeneity in accordance with the type and sequence of amino acid moiety and nature, length and branching of fatty acid chain and their moiety [28]. Lipopeptides are mainly classified into: Iturin biosurfactants, Surfactin biosurfactants and Fengycin biosurfactants.

Iturin biosurfactants: These are heptapeptides linked to $\beta$-amino fatty acid chain with a length of $\mathrm{C} 14$ to $\mathrm{C} 17$. There are many types of iturin: Iturin A, C, bacillomycin D, F, L, Lc and mycosubtilin. These are produced by $B$. subtilis strains. Iturin $A$ is the only lipopeptide which is produced by all $B$. subtilis strains. Iturin possess a very high antifungal activity against many yeast and fungal species whereas they have very limited antibacterial activity but no antiviral activity. Their fungi toxicity and their interaction are influenced because of their membrane permeabilization properties.
Surfactin biosurfactants: Surfactin was first discovered in the culture broth of B. subtilis in 1968 by Arima et al. [18]. It was named surfactin because of its exceptional surfactant activity [29]. They are cyclic lipopeptides and are heptapeptides interlinked with a $\beta$-hydroxy fatty acid. These are a mixture of isoforms A, B, C and D and are classified in accordance with the difference in their fatty acid sequence [30]. Surfactin lipopeptides are extensively studied. They possess a very potent haemolytic, antiviral, antimicrobial activity. Surfactin has a wide range of therapeutic applications than other biosurfactants.

Fengycin biosurfactants: These are deca-peptides with an internal lactone ring in the peptidic moiety and also with a $\beta$-hydroxy fatty acid chain (C14- C18). Fengycins are classified into Fengycins A and B. These are also known as plisplastatins. Fengycins are found to have a strong antifungal activity but are less haemolytic than iturins and surfactins. They really interact to lipid layers and to a certain extent have the ability to change cell membrane structure and permeability in a dose dependent way [28] (Figures 1 and 2).

\section{Lipopeptide biosynthesis}

B. subtilis lipopeptides are synthesized by non-ribosomal peptide synthetasis (NRPSs) or hybrid polyketide synthases and NRPSs (PKSs/ NRPSs). Biosynthesis of several hundred bioactive compounds is due to these molecular proteins. NRPS module contains about 1000 amino acids and is responsible for activation as an adenylate (A-domain), PCP domain (C-domain). Modules are mega enzymes organized in iterative functional units and perform the catalization of different reactions which leads to peptide transformation. Further, each module is sub-divided into several catalytic domains which are responsible for performing each biochemical reaction. SrfA-A, SrfA-B, SrfA-C are the three large open reading frame codes for surfactin synthesis. Products of Srf A-A and Srf A-B contains three modules while the last in Srf A-C. The fatty acid chain gets attached to the amino acid activated in the first module and synthesized product is released from the enzymatic
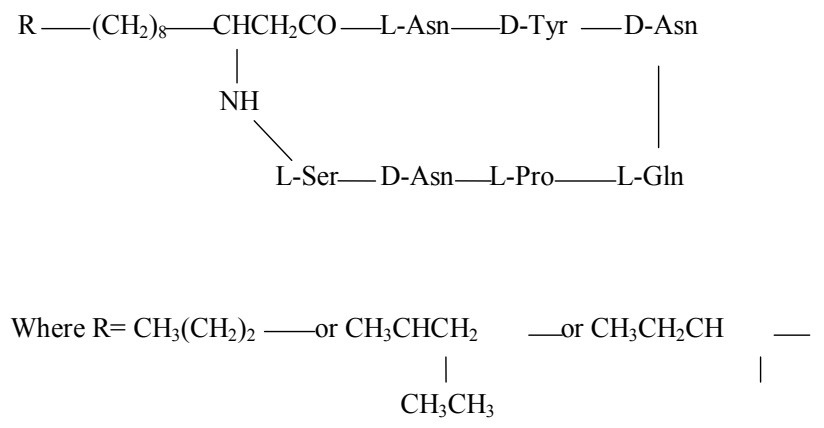

Figure 1: Structure of Iturin A.

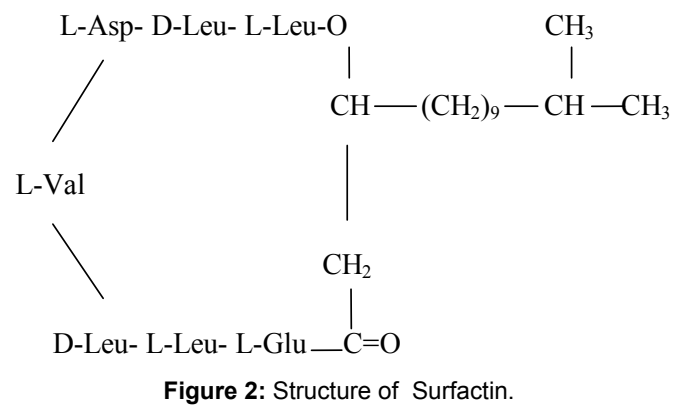


template due to the last activation of PCR domain. Further, the biosynthesis is initiated by second-thioesterase/acyltransferase which are encoded by a fourth gene of srfA-D. Fengycins are synthesized in the same way by NRPSs encoded by five open reading frames fen A-E. The two modules are contained by first three enzymes while the fourth enzyme contains three modules and the last enzyme contains one module. On the contrary, the iturin derivatives are synthesized by a hybrid complex (PKS-NRPSs). Itu d, Itu A, Itu B and Itu C are the four ORFs in the operon. The last three genes codes for first residue i.e. for itu $\mathrm{A}$, the subsequent four residues for itu $\mathrm{B}$ and the last two residues for itu C. Itu D encodes malonyl-CoA transacylase, moreover itu A contains genes related to PKSs and these genes are responsible for the last elongation and $\beta$-amination, i.e., the last steps for the biosynthesis of fatty chain before it is transferred to the amino acid of peptide moiety.

\section{Lipopeptides: Applications}

Lipopeptides as anti microbial agents: The literature shows that lipopeptides show very strong anti-fungal, anti-microbial, anti tumour, anti-viral and immune modulator properties. Plaza et al. [31] have showed that surfactin, a type of lipopeptide produced from Bacillus subtilis, growing on molasses is profound to have anti-fungal and anti-bacterial properties. They concluded that surfactin from Bacillus species growing on molasses inhibited the growth of four fungi out of ten tested. The results showed the fungi inhibited to the highest percentage was Botrytis cinerea A258 (about 50\% inhibition) followed by Sclerotina sclerotiorum K2291 (about 50 inhibition), Collectotrichum sclerotiorum A259 (about 40 \% inhibition), Phoma complanata A233 (about 38\% inhibition), lastly, Phoma exigua var. exigua A175 (about $20 \%$ inhibition). Further, for testing anti bacterial activity E. coli inhibition was demonstrated by agar plate inhibition assays and high growth was noted among $76 \%$ E. coli isolates.

Nielson et al. [32], found out a new cyclic depsipeptide from Pseudomonas fluorescens DR54, named viscosinamide which showed anti fungal properties against Phythium ultimum and Rhizoctonia solani. They concluded that the new CLPs possess both biosurfactant and antibiotic properties, thereby can be used as a potent biological control agent. Nielson et al. [33] reported a new cyclic compound tensin from Pseudomonas fluorescens strain 96.578 having anti-fungal activity against plant pathogenic fungus Rhizoctonia solani. Kruijt et al. [34] found a putisolvin like cyclic lipopeptide biosurfactant produced from $P$. putida 267 having zoosporicidal and anti-fungal activity. Moreover, the CLPs are also found to be vital in swarming motility and biofilm formation. The CLPs were found to be potent against fungitoxicity Phytophthora damping-off of cucumber.

Lipopeptides as immunomodulators: Infante-Duarte et al. [35] demonstrated that the lipopeptides derived from B. burgdorferi stimulate the IL-17 expression (Cytokine produced by activated murine cytotoxic T-cells) in both murine and human $\mathrm{T}_{\mathrm{H}}$ cells. They induce the IL-17 expression together with TNF- $\alpha$, so are coexpressed with other proinflammatory cytokines. Das et al. [36] demonstrated the anti microbial activity of a lipopeptide biosufactant produced from a marine Bacillus circulans. The produced biosurfactant showed a potent anti microbial activity against both gram positive and gram negative pathogenic and semi pathogenic microbial strains. Moreover, this biosurfactant was also found to be non haemolytic.

Lipopeptides in laundry and enhanced oil recovery: A.K. Mukherjee, [37] studied that Crude cyclic lipopeptide biosurfactant synthesized from two B. subtilis strains (DM-03 and DM-04). They showed that (CLP) is stable and compatible to use as laundry detergents. Kiran et al. [38] found a new lipopeptide biosurfactant produced from strain B. aureum. The biosurfactant produced can be employed successfully in enhanced oil recovery process in marine environments.

Sriram et al. [39] found a lipopeptide from E. fergusonii KLU01. The biosurfactant found to be resistant to manganese, iron, lead, nickel, copper and zinc. So, this biosurfactant possess a potential in hydrocarbon degradation and heavy metal bioremediation. Pathak and Kaharia, [40] studied the extracellular lipopeptide produced from endophytic Bacillus subtilis K1 which was taken from aerial of banyan. The strain has high heterogeneity with secreted mixtures of surfactins, iturins and fengycins. The lipopeptide biosurfactant resulted in about $43 \%$ enhanced oil recovery on laboratory scale sand pack column with four stroke engine oil.

Suwat Soonglerdsongpha [41] isolated a lipopeptide biosurfactant from Bacillus sp. GY19. The results showed that 1 - 3\% lipopeptide solutions had $80-100 \%$ oil displacement efficiency with Oman light oil, heavy oil, diesel oil and Arabian light oil. The activities were comparable to a commercial dispersant (Slickgone NS) and much higher than a synthetic surfactant (Tween 20). In addition, the lipopeptide solutions were stable at extreme salinity, $\mathrm{pH}$, and temperature. Consequently, foamate and powder containing lipopeptides could be used directly as dispersants for oil spill remediation.

Sriram et al. [42] found a lipopeptide biosurfactant produced from, a propitious bacterial strain isolated from oil contaminated soil Escherichia fergusonii KLU01. The strain emerges as a new class of biosurfactant producer with potential environmental and industrial applications, especially in hydrocarbon degradation and heavy metal bioremediation. (Table 1)

Lipopeptides in biomedical applications: Kuiper et al. [43], found two lipopeptides putisolvin 1 and II from P. putida strain PCL 1445. These are the first reported lipopeptides having 12 amino acids. Putisolvin 1 and II inhibit the biofilm formation of Pseudamonas on polyvinylchloride and they can also break down the biofilms of many Pseudomonas sp. which are formed on PVC. Rivardo et al. [44], characterized two biosurfactant producing strains $B$. subtilis and $B$. licheniformis. The two lipopeptides showed good anti-adhesion activity able to significantly inhibit the biofilm formation of two pathogenic strains i.e. E. coli CFT073 and S. aureus ATCC 29213 up to $97 \%$ and $90 \%$. It was observed that V9T14 biosurfactant was active on gram negative strain but ineffective against gram positive strain and vice versa for V19T21. Sriram et al. [45], identified the strain Bacillus cereus NK1 which produced a lipopeptide biosurfactant. The lipopeptide produced thus showed anti microbial activity and also inhibits the biofilm formation. The strain B. cereus NK1 (GU 167978) was isolated from soil sample. The resulting biosurfactant was able to inhibit the biofilm formation by $P$. aeroginosa and S. epidermidis. The maximum biofilm inhibition was found against S. epidermidis with $57 \%$ of inhibition percentage. The lipopeptide at conc. $15 \mathrm{mg} / \mathrm{ml}$ performed the maximum biofilm inhibition of both the test organism. The strain was also found to be resistant against ferrous sulphate, lead acetate and zinc sulphate.

Pradhan et al. [46] isolated a biosurfactant producing halophile from Lake Chilika, Odisha, India. The halophile was identified as Bacillus tequilensis $\mathrm{CH}$. The microbial surfactant produced by the halophile was lipopeptide. The biosurfactant was found to inhibit the biofilm of E. coli and Streptococcus mutans at the minimum concentration of $50 \mu \mathrm{g} / \mathrm{ml}$ on both hydrophilic and hydrophobic surface. 
Citation: Walia NK, Cameotra SS (2015) Lipopeptides: Biosynthesis and Applications. J Microb Biochem Technol 7: 103-107. doi:10.4172/19485948.1000189

Lipopeptides in nanotechnology: According to Plaza et al. [47] Lipopeptide biosurfactants can also be used in the synthesis of nanoparticles. According to Reddy et al. [48] Surfactin can be used as both the template and stabilizing agent in the synthesis of silver and gold nanoparticles. The stable gold nanoparticles were synthesized by reducing aqueous $\mathrm{AuCl} 4$ using sodium borohydrate in the presence of surfactin which was produced by Bacillus subtilis.

Reddy et al. [49] used Surfactin as a templating-agent stabilizer to make nanostructured zinc oxide rose-like arrangements using the precipitation method. The rose-like structures were found to be 9 to $13 \mathrm{~nm}$ thick.

Singh et al. [50] used surfactin from Bacillus amyloliquifaciens for the synthesis of stable cadmium sulfide nanoparticles (CdS-NPs). The yield of the surfactin was found to be $160 \mathrm{mg} / \mathrm{L}$. CdS nanoparticles were synthesized directly from this crude surfactin biosurfactant. The produced nanoparticles covered with surfactin were found to be stable for up to six months without any apparent change in their structure.

\section{Conclusion}

Initially, the use of lipopeptides was limited only to the enhanced oil recovery and to bioremediation. However, with the changing scenario over the last decade, lipopeptides have proved to be ecofriendly, biodegradable, less toxic and more biocompatible than the chemical surfactants, their use in pharmaceuticals, food and cosmetic industry has been increased to a great extent. Due to their anti-fungal, anti-bacterial, anti tumour and anti-viral properties they are now showing their potential for use as major immunomodulatory molecules and anti-adhesive agents. They are also being used for gene transfection, as ligands for binding immunoglobulins. They proved to be very useful in eradicating nosocomial infections caused by different microorganisms by inhibiting their biofilms. Microbial surfactants may also be incorporated into probiotic preparations to fight urogenital tract infections and pulmonary immunotherapy. Biosurfactants can also be used in production of green electricity as biosurfactants increase the surface area and emulsify hydrophobic compounds like oil $(\mathrm{O} /$ water and W/O emulsions). This could eventually lead to increase production of the products (Biofuel).

Therefore we can see, that over the period of time, lipopeptide biosurfactants have traveled a long way from being just seen as some chemical agents having their applications in environmental biotechnology to being seen as vital chemical moieties having major promising roles in human healthcare as well.

\section{References}

1. Müller MM, Kügler JH, Henkel M, Gerlitzki M, Hörmann B, et al. (2012) Rhamnolipids--next generation surfactants?J Biotechnol 162: 366-380.

2. Fish NM, Allenbey DJ, Lilly MD (1982) Oxidation of n-alkanes: growth of Pseudomonas putida. European Journal of Applied microbiology and biotechnology 14: 259-262.

3. Itoh S, Suzuki T (1972) Effect of rhamnolipids on Pseudomonas aeruginosa mutant deficient in $n$-paraffin utilizing ability. Agricultural and Biological Chemistry 36: 2233-2235.

4. Das P Mukherjee S, Sen R (2008) Antimicrobial potential of a lipopeptidebiosurfactant derived from a marine Bacillus circulans. J Appl Microbiol 104: 1675-1684.

5. Wagner $F$ (1983) Production and chemical characterization of surfactants from Rhodococcuserythropolis and Pseudomonas $\mathrm{sp}$. mub grown on hydrocarbons. Microbial Enhanced Oil recovery, pp. 55-60.

6. Edwards JR, Hayashi JA (1965) Structure of a rhamnolipid from Pseudomonas aeruginosa. Arch Biochem Biophys 111: 415-421.
7. Syldatk C, Lang S, Matulovic U, Wagner F (1985) Production of four interfacia active rhamnolipids from $n$-alkanes or glycerol by resting cells of Pseudomonas species DSM 2874. Z Naturforsch C 40: 61-67.

8. Syldatk C, Wagner F (1987) Production of Biosurfactants. In:Biosurfactants and Biotechnology 25: 89-120.

9. Reiling HE, Thanei-Wyss U, Guerra-Santos LH, Hirt R, Käppeli O, et al (1986) Pilot plant production of rhamnolipidbio surfactant by Pseudomonas aeruginosa.Appl Environ Microbiol 51: 985-989.

10. Linhardt RJ, Bakhit R, Daniels L, Mayerl F, Pickenhagen W (1989) Microbially produced rhamnolipid as a source of rhamnose. Biotechnol Bioeng 33: 365368.

11. Klekner V, Kosaric N (1993) Biosurfactants for cosmetics. In: Kosaric N (ed.) Biosurfactants: Production-Properties-Applications. Marcel Dekker Inc, NY,pp. 373-393.

12. Nitschike M, Costa SGVA (2007) Biosurfactactants in food industry. Trends in Biotechnology 18: 252-259.

13. Kosaric N(2001) Biosurfactants in industry. Pure and Applied Chernistry. 64 1731-1737.

14. Cameotra SS, Makkar RS (2004) Recent applications of biosurfactants as biological and immunological molecules.CurrOpinMicrobiol 7: 262-266.

15. Makkar RS, Cameotra SS (2002) An update on the use of unconventional substrates for biosurfactant production and their new applications.ApplMicrobiol Biotechnol 58: 428-434.

16. Rodrigues L, Banat IM, Teixeira J, Oliveira R (2006) Biosurfactants: potential applications in medicine. J Antimicrob Chemother 57: 609-618.

17. Sachdev DP, Cameotra SS (2013) Biosurfactants in agriculture. Appl Microbiol Biotechnol 97: 1005-1016.

18. Kakinuma A, Arima K, Tamura G (1968)Surfactin, a crystalline peptidelipid surfactant produced by Bacillus subtilis: isolation, characterization and its inhibition of fibrin clot formation. Biochem Biophys Res Commun 3: 488-494.

19. Peypoux F, Michel G, Delcambe L (1976) The structure of mycosubtilin, an antibiotic isolated from Bacillus subtilis (author's transl). Eur J Biochem 63 391-398.

20. Besson F, Peypoux F, Michel G, Delcambe L (1977) The structure of bacillomycin $\mathrm{L}$, an antibiotic from Bacillus subtilis (author's transl). Eur $\mathrm{J}$ Biochem 77: 61-67.

21. Eshita SM, Roberto NH, Beale JM, Mamiya BM, Workman RF (1995) BacillomycinLc, a new antibiotic of the iturin group: isolations, structures, and antifungal activities of the congeners. J Antibiot (Tokyo) 48: 1240-1247.

22. Peypoux F, Guinand M, Michel G, Delcambe L, Das BC, et al. (1978) Structure of iturine A, a peptidolipid antibiotic from Bacillus subtilis. Biochemistry 17 3992-3996.

23. Peypoux F, Besson F, Michel G, Delcambe $L$ (1981) Structure of bacillomycin $\mathrm{D}$, a new antibiotic of the iturin group. Eur J Biochem 118: 323-327.

24. Wakayama S, Ishikawa F, Oishi K (1984) Mycocerein, a novel antifungal peptide antibiotic produced by Bacillus cereus. Antimicrob Agents Chemother 26: 939-940.

25. Volpon L, Besson F, Lancelin JM (2000) NMR structure of antibiotics plipastatins $A$ and $B$ from Bacillus subtilis inhibitors of phospholipase $A(2)$. FEBS Lett 485: 76-80.

26. Nishikiori T, Naganawa H, Muraoka Y, Aoyagi T, Umezawa H (1986) Plipastatins: new inhibitors of phospholipase A2, produced by Bacillus cereus BMG302-fF67. II. Structure of fatty acid residue and amino acid sequence.J Antibiot (Tokyo) 39: 745-754

27. Cho SJ,Lee SK, Cha BJ, Kim YH, Shin KS (2003) Detection and characterization of the Gloeosporiumgloeosporioides growth inhibitory compound iturin A from Bacillus subtilis strain KS03. FEMS Microbiology Letters 223: 47-51.

28. Hathout Y, Ho YP, Ryzhov V, Demirev P, Fenselau C (2000) Kurstakins: new class of lipopeptides isolated from Bacillus thuringiensis. J Nat Prod 63: 1492-1496.

29. Ongena M, Jourdan E, Adam A, Paquot M, Brans A, et al. (2007) Surfactin and fengycinlipopeptides of Bacillus subtilis as elicitors of induced systemic resistance in plants. Environ Microbiol 9: 1084-1090. 
Citation: Walia NK, Cameotra SS (2015) Lipopeptides: Biosynthesis and Applications. J Microb Biochem Technol 7: 103-107. doi:10.4172/19485948.1000189

30. Peypoux F, Bonmatin JM, Wallach J (1999) Recent trends in the biochemistry of surfactin. Appl Microbiol Biotechnol 51: 553-563

31. Fracchia L (2012) Biosurfactants and Bioemulsifiers. Biomedical and Related Applications - Present Status and Future Potentials 14.

32. Plaza GA, Turek A, Król E, Szczyglowska R (2013) Antifungal and antibacterial properties of surfactin isolated from Bacillus subtilis growing on molasses. African Journal of Microbiology Research 7:3165-3170.

33. Nielsen TH, Christophersen C, Anthoni U, Sørensen J (1999) Viscosinamide, a new cyclic depsipeptide with surfactant and antifungal properties produced by Pseudomonas fluorescens DR54. J Appl Microbiol 87: 80-90.

34. Nielsen TH, Sørensen D, Tobiasen C, Andersen JB, Christophersen C, et al. (2002) Antibiotic and biosurfactant properties of cyclic lipopeptides produced by fluorescent Pseudomonas spp. from the sugar beet rhizosphere.Appl Environ Microbiol 68: 3416-3423.

35. Kruijt M, Tran H, Raaijmakers JM (2009) Functional, genetic and chemical characterization of biosurfactants produced by plant growth-promoting Pseudomonas putida 267. J Appl Microbiol 107: 546-556.

36. Infante-Duarte C, Horton HF, Byrne MC, Kamradt T (2000) Microbial lipopeptides induce the production of IL-17 in Th cells. J Immunol 165: 61076115.

37. Das P, Mukherjee S, Sen R (2008) Antimicrobial potential of a lipopeptidebiosurfactant derived from a marine Bacillus circulans. J App Microbiol 104: 1675-1684.

38. Mukherjee AK (2007) Potential application of cyclic lipopeptidebiosurfactants produced by Bacillus subtilis strains in laundry detergent formulations. Letters in Applied Microbiology 45: 330-335

39. Kiran T (2009) Optimization and characterization of a new lipopeptidebio surfactant produced by marine Brevibacterium aureum MSA13 in solid state culture. Bioresource Technology 101:2389-2396.

40. SriramMI (2011), Novel lipopeptidebiosurfactant produced by hydrocarbon degrading and heavy metal tolerant bacterium Escherichia fergusonii KLU01 as a potential tool for bioremediation. Bioresource Technology. 102:9291-9295.
41. Pathak KV, Keharia HK (2013) Application of extra cellular lipopeptidebio surfactant produced by endophytic Bacillus subtilis $\mathrm{K} 1$ isolated from aerial roots of banyan (Ficusbenghalensis) in microbially enhanced oil recovery (MEOR). 3 Biotech 4: 41-48.

42. NichakornKhondeea, SittiTathonga, OnruthaiPinyakongb, Rudolf Müllerc Suwat Soonglerdsongpha, et al (2014) Lipopeptide biosurfactant production by chitosan-immobilized Bacillus sp. GY19 and their recovery by foam fractionation. Biochemical Engineering Journal 93:47-54.

43. Kuiper I, Lagendijk EL, Pickford R, Derrick JP, Lamers GE, et al. (2004) Characterization of two Pseudomonas putidalipopeptidebiosurfactants putisolvin I and II, which inhibit biofilm formation and break down existing biofilms. Mol Microbiol 51: 97-113.

44. Rivardo F, Turner RJ, Allegrone G, Ceri H, Martinotti MG (2009) Anti-adhesion activity of two biosurfactants produced by Bacillus spp. prevents biofilm formation of human bacterial pathogens. Appl Microbiol Biotechnol 83: 541-553.

45. Sriram MI, Kalishwaralal K, Deepak V, Gracerosepat R, SrisakthiK,et al. (2011) Biofilm inhibition and antimicrobial action of lipopeptidebiosurfactant produced by heavy metal tolerant strain Bacillus cereus NK1. Colloids Surf B Biointerfaces 85: 174-81

46. Pradhan AK, Pradhan N, Mall G, Panda HT, Sukla LB, et al. (2013) Application of lipopeptidebiosurfactant isolated from a halophile: Bacillus tequilensis $\mathrm{CH}$ for inhibition of biofilm. Appl Biochem Biotechnol 171: 1362-1375.

47. Paaza GA, Chojniak J, Banat IM (2014) Biosurfactant mediated biosynthesis of selected metallic nanoparticles. Int J MolSci 15: 13720-13737.

48. Reddy AS, Chen CY, Baker SC,Chen CC, Jean JC, et al.(2009) Synthesis of silver nanoparticles using surfactin: A biosurfactant as stabilizing agent. Mater. Lett, 63:1227-1230.

49. Reddy AS, Kuo YH, Atla SB, Chen CY, Chen CC, et al. (2011) Lowtemperature synthesis of rose-like $\mathrm{ZnO}$ nanostructures using surfactin and their photocatalytic activity. J Nanosci Nanotechnol 11: 5034-5041.

50. Singh BR, Dwivedi S, Al-Khedhairy AA, Musarrat(2011) Synthesis of stable cadmium sulfide nanoparticles using surfactin produced by Bacillus amyloliquifaciens strain KSU-109. Colloids Surf. B Biointerfaces 85:207-213. 